\title{
Image-building Markers in Small Stories: Evidence from Chinese Snooker Commentary \\ Wang Cong-cong
}

\begin{abstract}
South China Business College Guangdong University of Foreign Studies, Guangzhou, China, 510000
\end{abstract}

308949803@qq.com

Keywords: Chinese snooker commentary; image building; small stories.

Abstract: This paper tries to discern the role of small stories in building different-nationality players' images with the focus primarily on the content analysis of appellations and tenses. The discoursal analysis shows that the linguistic construction of the Chinese player's image is more diverse than that of the foreign player's and the commentators usually show a strong inclination towards building the Chinese player as a promising winner overtly, while building the foreign player as an ultimate loser covertly.

\section{Introduction}

Sports announcer talk (SAT) can be described as a conversation between a sports announcer and an expert consultant, whose talk is featured by professional knowledge and typical personal style. The two persons are entitled the power to organize the visual information into verbal one by selecting what seems important and excluding what seems unimportant, and then pass on the encapsulated message to the audience [1]. As Sullivan states, they are a unique media source as they blend objective and judgmental components with the purpose of not only reporting an event but also dramatizing the event [2]. Chinese snooker commentary (CSC), as a special branch of SAT, has not yet been studied from discourse perspective $[3,4,5,6]$. This paper has chosen the final of the 2009 UK Championship as the research data with the purpose of unveiling the role of small stories in live televised games.

\section{Linguistic construction of image in small stories}

As Bamberg states, "when we tell stories, we do a little more than when we speak. In the stories......characters inside the story world gain their existence in story performance; they are creations or constructions of the narrator(s)" [7]. Taking off from this very simple but basic orientation as the starting point, the author has probed into the way the commentators construct the images of different-nationality players by narrating small stories.

Based on the topic and the protagonist in each story, the categories and the number of small stories have been counted and summarized into the following table.

Table 1 Small Stories in CSC (2009 UK Championship)

\begin{tabular}{|c|c|c|}
\hline & Ding Junhui & John Higgins \\
\hline Anecdotes & 7 & 7 \\
\hline Family Background & 0 & 1 \\
\hline Past Experience & 6 & 7 \\
\hline Advantages and Disadvantages & 12 & 4 \\
\hline Prospect & 5 & 0 \\
\hline Total & 30 & 19 \\
\hline Percentage & $60 \%$ & $40 \%$ \\
\hline
\end{tabular}

From the table above, we can be impressed by the fact that the number of small stories featuring Ding is larger than that featuring Higgins and Prospect narratives have only been spared to the Chinese player. Prospect is the commentators' anticipation about the player's chance to win the 
game. In this sense, it is plain to the audience that the commentators intend to depict Ding rather than Higgins as the winner of the game.

\subsection{Membership differentiation by appellations}

Membership refers to the state of being one member of a group and can be realized through more than one way, among which appellation is a favored and popular means to differentiate from others and shows solidarity. From the following example, we can notice the function of the appellation is to exclude the foreign player out of the camp where the commentators and Chinese fans stay, and include the Chinese player into the camp.

Example 1:

这场比赛呢，是在我国著名选手丁俊晖和天王希金斯之间展开的对决。

(This match is between our country's famous player Ding and King Higgins.)

Furthermore, among the various small stories, the commentators have called Ding “小晖” (Xiao Hui) nine times at some exciting moment, which contrasts with the always-title "Higgins" for the foreign player although he also has a nickname (Wizard). In this context, “小晖” (Xiao Hui) shows the commentators' support, fancy and intimacy to the Chinese player. Compared with "Higgins", “小晖” (Xiao Hui), to some extent, sends a kind of information and hint to the audience that the Chinese player is an amiable person on the same side, while “ (天王) 希金斯” (King Higgins) renders the foreign player distant to the audience. The following is one typical example explaining what the author argues about. Here $\mathrm{J}$ stands for Jiang Yi, the announcer, while P stands for Pang Weiguo, the invited expert.

Example 2

P: 希金斯送大礼啊,嗯.

$\mathrm{J}$ : 漂亮！现在说这局其实本来就应该是小晖的。

P: (轻笑)

$\mathrm{J}$ : 刚才那一杆防守做得多好啊（轻笑）。

(P: Higgins has sent a great present. Good.

J: Wonderful. it is safe to say that this frame should go to Xiao Hui.

P: haha...

J: What a splendid safety play just now! Haha...)

\subsection{Diachronic change of images}

With the focus on image building, we have delimited the time on the basis of the match. Grounded on such a delimitation, the distribution of tenses has been counted and compared in Table 2 .

Table 2. Tense distribution among small stories in CSC

\begin{tabular}{|c|c|c|c|}
\hline & Past Tense & Present Tense & Future Tense \\
\hline Chinese Player & 3 & 16 & 11 \\
\hline Foreign Player & 5 & 14 & 0 \\
\hline
\end{tabular}

The most conspicuous point in Table 2 is the exclusive distribution of the future tense to the Chinese player. From the perspective of image construction, we can assume that the commentators have been devoted to constructing three-layered images of the Chinese player: past image, present image and future image, while the images of the foreign player are just two-layered. From the following examples, the future image of the Chinese player the commentators intend to construct is self-evident from the italicized words, that is, the winner of the match.

Example 3

对丁俊晖来讲呢, 这是一场职业生涯的冲冠之战。

(For Ding, this will be a battle for championship.)

To conclude, the image construction of each player in small stories has gone through a diachronic change. Past image will not be probed into further as it has little to do with the present match. Present image of each player has been touched upon and analyzed in the author's another 
paper [8] and therefore will not be further explained. As to the players' future image, the commentators are dedicated to building the Chinese player's winner image and on the other hand backgrounding the foreign player into a loser role.

\section{Intentions concealed in small stories}

To unveil the intentions behind discursive strategies used to build each player's image, we have to take the context into account. Take the following narrative that appears after the BBC director presents the statistics of rest success as an example.

Example 4

$\mathrm{P}$ : 我们看刚才这是架杆的一个成功率。

$\mathrm{J}$ : 嗯。

P: 希金斯还是高一点刚才用架杆。

$\mathrm{J}$ : 按说丁俊晖的架杆在当今的斯诺克台应该不输于任何一个对手。

$\mathrm{P}$ : 没错, 这只是这场啊。

$\mathrm{J}$ : 恩, 从小就站在板登上 (轻笑) 拿着架杆儿跟人打, 这个架杆儿应该是像手指一样的熟。

(P: We can see that this is the statistics of rest success.

J: Yes.

$\mathrm{P}$ : Higgins's rest success is a bit higher.

$\mathrm{J}$ : It is supposed that Ding Junhui should not be inferior to any snooker player in rest.

P: That's right. It just represents this match.

J: Yes. Ding has played snooker with the rest since he was a child. The rest is just like his finger. )

As the narrative shows, the first three lines just state the fact that Higgins's rest success is higher than Ding's. However, after ten seconds, the commentators turn to repair the Chinese player's image by “....不输于任何一个对手” (not inferior to any snooker player). To make their statement more persuasive, the commentators continue to speak of the Chinese player's childhood experience. The intention concealed in the narrative seems to reveal itself by the time the commentators stand up for the Chinese player and means to repair his damaged image, which is similar to the function of speech acts EXCUSE-FINDING and PITYING. However, this kind of narratives have never been spared to the foreign player. In contrast to the overtly expectation for the Chinese player to be the winner, the expectation for the foreign player to be the loser has been revealed implicitly here and there. For example:

Example 5

$\mathrm{P}$ : 目前前五局是谁开球谁输

$\mathrm{J}$ : 哎, 还真是啊。希金斯率先开球，对（轻笑）。

P: (轻笑) 因为现在刚好是这个比分啊, 这个梅花卷轴般的上来的。

$\mathrm{J}$ : 嗯

$P$ : 都是丁俊晖一直领先追平领先追平, 现在又领先。

$\mathrm{J}$ : 对。当然这跟开球没关系啊 (轻笑)。

P: (轻笑)

$\mathrm{J}$ : 开球没有失误（轻笑），这个巧合。

(P: Up to now, the one who breaks the frame is always the loser in the first five frames.

$\mathrm{J}$ : Hey! Really. Higgins is the one to break this frame. Yes! Ha-ha

P: Ha-ha. Now the scores are like plum blossom with Ding being leading and then being leveled recurrently. Now Ding is in the lead again.

J: Right. But it has nothing to do with the break. Ha-ha.

P: Ha-ha.

J: no one made a mistake in the break. Ha-ha. It's just a coincidence.)

As Example 5 shows, $\mathrm{P}$ points out the first five frames follow a regular pattern that the one who breaks the frame has always been the loser. Therefore, the audience can deduce the latter part of "希 
金斯率先开球” (Higgins is the one to break this frame) is “这局轮到希金斯输了” (it is Higgins's turn to lose). By contrast, when it is the Chinese player's turn to break, the commentators swing to the Chinese player with the hope of him breaking the pattern, as the following narrative shows.

Example 6

$\mathrm{J}$ : 哎呀, 看看丁俊晖能不能打破庞指导说的这条定律啊（轻笑）。

P: (轻笑)

$\mathrm{J}$ : 谁先开球谁输。

(J: Ah. Let's see whether Ding can break the law that Instructor Pang refers to. Ha-ha.

P: Ha-ha.

$\mathrm{J}$ : the one to break will lose the frame.)

\section{Summary}

The linguistic means for image construction of the Chinese player are more diverse than that of the foreign player. By differentiation of appellations and tenses, the image of Chinese player has been more multiple-layered. The commentators' preference and intention to build the Chinese player as a winner has been manifested to the full compared to the hidden indication of the foreign player's loser image. As to the intentions cloaked in the small stories, they can be easily detected if the context is taken into account: to repair the Chinese player's image; to build the Chinese player as a winner explicitly; to construct the foreign player as a loser implicitly.

\section{Acknowledgement}

This paper was funded by the English Language \& Literature, one of the Key Programs in Guangdong 2016 (GDTX170109), and the Association Project of Comparative Study of English and Chinese in the New Era (NG2017298).

\section{References}

[1] T. Gitlin, The whole world is watching, Berkeley: University of California Press, 1980.

[2] D. B. Sullivan, Commentary and viewer perception of player hostility: adding punch to televised sports, Journal of Broadcasting and Electronic Media, vol.35, pp. 487-504, 1991.

[3] C. A. Billings, K. K. Halone and E. B. Denham, "Man, that was a pretty shot": an analysis of gendered broadcast commentary surrounding the 2000 men's and women's NCAA final four basketball championships, Mass Communication and Society, vol.5(3), pp. 295-315, 2009.

[4] S. S. Shen, Linguistic realization of commentary stance: evidence from Chinese table tennis programmes, Beijing: Science Press, 2010.

[5] J. Sterkenburg, A. Knoppers and S. Leeuw, Constructing racial/ethnic difference in and through Dutch televised soccer commentary, Journal of Sport and Social Issues, vol.36, pp. 422, 2012.

[6] A. Barnfield, Soccer, broadcasting, and narrative: on televising a live soccer match, Communication \& Sport, vol.1(4), pp. 321-341, 2013.

[7] M. Bamberg, Positioning with Davie Hogan: stories, tellings and identities // C. Daiute and C, Lightfoot, Narrative analysis: studying the development of individuals in society, London: Sage, pp. 135-157, 2004.

[8] C. C. Wang, Linguistic construction of players' images: evidence from live snooker commentary, Journal of Heilongjiang College of Education, vol.6, pp. 123-126, 2018. 